REV. PER. BIOL. 4 (1-2): 21-24, DIC. 1992

\title{
PREVALENCIA DE Sarcocystis sp. EN VACUNOS, OVINOS Y CAPRINOS BENEFICIADOS EN LOS CAMALES DE LIMA
}

\author{
Julia Castro * y Guillermo leguía * * \\ * Insituto de Investigaciones de Ciencias Biológicas "Antonio Raimondi" Fac. \\ de Ciencias Biológicas, Universidad Nacional Mayor de San Marcos. \\ * Laboratorio de Parasitología. Fac. de Medicina Veterinaria, Universidad Na- \\ cional Mayor de San Marcos, Lima, Pert.
}

\section{SUMARIO}

Se ha realizado el presente estudio para determinar la prevalencia de Sarcocystis sp. en vacunos, ovinos y caprinos utilizando el método del triquinoscopio con muestras de tejido cardíaco y esófago. Los resultados mostraron que de 85 muestras de tejido cardíaco de ganado vacuno, 76 fueron positivas (89.5\%); de 134 muestras de ganado ovino 122 fueron positivas $(91.04 \%)$ mientras que de 63 muestras de ganado caprino solo en $33(52.4 \%)$ se encontró la presencia del parásito. En cuanto a las muestras de esófago los porcentajes de parasitismo fueron los siguientes: $2 \%$ para el vacuno; $39.8 \%$ para el ovino y $76.2 \%$ para el caprino.

Estos valores indicaron que el mayor parasitismo en vacunos y ovinos está localizado en el corazón, mientras que en caprinos el órgano más infestado es el esófago. Por lo tanto existe un elevado parasitismo por Sarcocystis sp. en eI ganado beneficiado para consumo humano.

\section{SUMMARY}

A study about the prevalence of Sarcocystis sp. in bovine, ovine and goat cattle have been performed using the Trichinoscopy method into heart and esophagus tissues. The results showed that 76 samples of heart tissues from bovine positive over a total of 85 samples (89.5\%); will 122 sampless from ovine were positive over a total of 134 samples $(91.04 \%)$. In the same tissue of goat only 33 samples (52.4\%) Sarcocystis was found.

In esophagus the parasitism average was as follow: $2 \%$ in bovine; 39.8 in ovine and 76.2 in goat.

These results achived trat the mayor parasitism in bovine and ovine is 10 cated into the heart; whilst in goat the esophagus is the tissue more infectac Therefore a hig parasitism by Sarcocystis sp. has been registred in the meat of cattle used as a human food.

\section{INTRODUCCION}

El Sarcocystis, es una coccidia del titipo heterogéneo obligatorio en el cual el hombre y los carnivoros son los hospederos definitivos y el ganado (vacuno, caprino y camélidos) constituyen los hospederos intermediarios, en los cuales se realiza la reproducción sexual en el en dotelio vascular y muscular del hospeda dor. (Foryer, 1974; Leek 1977). En nuestro medio, pocos son los estudios realizados sobre prevalencia y distribución de la Sarcocystiosis; no obstante ser este parasitismo de especial importancia en la industria pecuaria, debido a que se pro- 
duce cuadros agudos y crónicos con muerte $y$ aborto, en el ganado que se beneticia para consumo humano (Fayer, 1977).

Por otro lado Sarcocystis, es importante en Salud Pública, se reportan una tasa de Sarcocystiosis humana del orden del 6 al $10 \%$, por el consumo de carne cruda o mal cocida ocasionando una sintomatolo. gía semejante a una gastroenteritis, por la acción de sustancias tóxicas (Gorman 1984; Fayer 1986).

En el hombre la Sarcocystiosis muscular generalmente asintomática (Aryeetey, 1976) en el diagnóstico histológico no se observa reacción inflamatoria asociado con la presencia del parásito en los musculos, sin embargo, Dubey (1976) reportó sintomas de edema, debilidad, dolor muscular, miositis, eosinofilia, fiebre y broncoespasmos.

En el presente estudio, se ha hecho un análisis de la prevalencia de Sarcocystis en especies de ganado más comunmente utilizados en la alimentación humana con la finalidad de establecer los riesgos a los que está expuesta la población de Lima al ingerir carne infecto. da por Sarcocystis.

\section{MATERIAL Y METODOS}

Se investigó el ganado beneficiado para consumo humano, en el Camal de Yerbateros de la Ciudad de Lima. La procedencia del ganado fueron los Departamentos de Junín, Ayacucho, Arequipa, Ica; Cajamarca y Lima.

El grupo de estudio estuvo constituído por 85 muestras de ganado vacuno. 134 ovino y 63 caprinos. Las muestras se tomaron al azar y colectándose porcio nes de corazón y esófago, se procedieron $\alpha$ identificar los microquistes utilizando la técnica del triquinoscopio (Leguíc, 1980) Luego se procedió a la identuficación toxonómica siguiendo los criterioz descritos por Dubey (1976) y Levine (1977).

\section{RESULTADOS}

1. Se examinaron 282 animales beneficiados para consumo en el Camal de Yerbateros de Lima.

2. El ganado vacuno, ovino, caprino beneficiado para la alimentación eir nuestro medio presenta una elevada indidencia de Sarcocystis.

3. De los estudios realizados, se obtuvo la mayor prevalencia en corazón de ovino ( $91.04 \%)$, siguiendole el gana do vacuno ( $89.5 \%$ ) y el caprino $(52.4 \%)$, como se observa en el Cladro Nro. 01.

4. A través de la observación micros cópica del esófago se llegó a confirmar el parásito en caprinos (76.2\%) en ovinos $(39.6 \%)$ y en vacunos (2.4\%). Cuadro Nro. 02 .

CUADRO NO. 1

PREVALENCIA DE Sarcocystis sp. A TRAVES DE LA OBSERVACION MICROSCOPICA DEL CORAZON

\begin{tabular}{lcrcc}
\hline \multirow{2}{*}{ Ganado } & Total & \multicolumn{2}{c}{ Positivos } \\
& Examinados & No. & $\%$ \\
\hline & & 76 & 89.5 \\
VACUNO & 85 & 122 & 91.04 \\
OVINO & 134 & 33 & 52.40 \\
CAPRINO & 63 & & \\
\hline
\end{tabular}

CUADRO NO. 2

PREVALENCIA DE Sarcocystis sp. A TRAVES DE LA OBSERVACION MICROSCOPICA DEL ESOFAGO

\begin{tabular}{lcrr}
\hline \multirow{2}{*}{ Ganado } & Total & \multicolumn{2}{c}{ Positivos } \\
\hline & Examinados & No. & $\%$ \\
\hline VACUNO & 85 & 2 & 2.4 \\
OVINO & 134 & 53 & 39.6 \\
CAPRINO & 63 & 48 & 76.2 \\
\hline
\end{tabular}




\section{DISCUSION}

Arnao (1951), reporta la presencia de Sarcocystis sp. en ovinos de los Departamentos de Lima y Pasco. Guerrero (1967), estudiando la Sarcocystiosis de alpacas encontró los siguientes porcentajes de positividad de acuerdo a los órganos parasitados: corazón $100 \%$, esófago $99.5 \%$, músculo del cuello $87.5 \%$ y músculo de la pierna $95.5 \%$

Castro (1974) recalizó estudios de Sarcocyslis de llamas, del Departamento de Puno, encontrando que el $98.4 \%$ de positividad en las observaciones ma croscópicas del esófago y músculo de la pierna; en el examen histológico demostró la presencia de microquistes en el corazón llegando a un porcentaje de $98.4 \%$ y $90.1 \%$ en diafragma.

Leguía (1980), estudia la prevalencia de Sarcocystis en ovinos y vacunos dei Valle del Mantaro, hallando prevalencias del orden del $90-100 \%$ de quistes de Sarcocystis respectivamente.

Arias (1983), realizó estudios sobre prevalencia de Sarcocystis en ovinos y caminos de la zona de Cerro de Pasco determinando la presencia del parasito en el $100 \%$ y $62 \%$ de animales respectiva mente.

Cuentas (1985), al examen microscopico de corazón y esófago de animales beneficiados para consumo en un Camal de Lima, encontró una incidencia dei $100 \%$ en vacunos en corazón y esófago $93 \%$ en músculo cardíaco y $83 \%$ en esófago de ovinos y en caprinos $68 \%$ y $32 \%$ en corazón y esófago respectivámente. Al examen macroscópico no se evidencio ningún caso positivo.

Es interesante observar en nuestros resultados los porcentajes de $89.5 \%$ y $91.04 \%$ de infección en músculo cardíaco de ganado vacuno y ovino respectivamente considerando que el corazón de estos animales es generalmente consumido lue- go de una cocción ligera o moderada, tenemos que concluir que los riesgos de infección en el hombre son igualmente elevados requiriendose por tanto la difusión de medidas preventivas para proteger a la población. Siendo la Sarcocystiosis aún más elevada en alpacas y llamas como ya se mencionó, no sólo la población estaría expuesta, sino las comunidades campesinas de nuestra serranías que consumen principalmente carne de camélidos. Por ello creemos importante ampliar este estudio a otros órganos y musculatura estriada en general, para poder conocer la verdadera dimensión de este problema de Salud Pública.

\section{REFERENCIAS}

ARIAS, J. 1983. Prevalencia de Sarco. cystis sp. en ovinos y caninos de la Zona de Pasco. Tesis Ing. Zootecnista. Univ. Nac. Daniel Alcides Carrión. Cerro de Pasco.

ARNAO de MC GREGOR, M. 1951. Parásitos identificados en el Instituto Nacional de Biología Animal 19400. 1951. Ministerio de Agricultura. Dirección de Ganadería de Lima. Rev Inst. Nac. Biología Animal $2: 23$

ARYEETEY, Mary and PIEKARSKI, G. (76-81).

1976. Serologische Sarcocystis studien and men schen und ratten. Z. Para sitenic 50: 109-124.

CASTRO, Julio. 1974. Sarcocystis auche niae en llamas (Lama glama). Rev. Inv. Pec. (IVITA) U.N.M.S.M. $3(1)$. 91.92.

CUENTAS, R. 1985. Prevalencia de Sar cocysits sp. en vacuno, ovinos y ca. prinos beneficiados en el Camal de Yerbateros de la ciudad de Lima. Tesis Bach. Med. Veterinaria UNMSM.

DUBEY, J. 1976. A review of Sarcocystis of domestic onimals and other coccl.

FAYER. R.; JOHNSON, A. and LUNDE, M. Vet. Med. Asoc. 196: 1061-1078.

FAYER, R. 1974. Gametogony of Sarco. cystis species in cell culture. Science 175: 65-67. 
FAYER, R.; JOHNSON, A. and LUNDE, $M$. 1977. Abortion and other signs of disease in cows experimentally infec ted with Sarcacystis from dogs. I. Inf. Disease 134: 624-628.

GORMAN, T.; ALCAINO, H. and MUNOOZ, H. 1984. Sarcocystis in guanaco ( $L a-$ ma guanicoe) and effect of temperature on its viability. Veterinary $\mathrm{Pa}$. rasitology 15: 95-101.

GUERRERO, C.; HERNANDEZ, J. Y ALVA J. 1967. Sarcocystis en alpacas. Rev.
Fac. Med. Vet. U.N.M.S.M. Vol. 21 : 69-73.

LEEK, R.; FAYER, R. and JOHNSON, J. 1977. Sheep experimentally infected with Sarcocystis from dorgs. I. Disease in young lambs. J. Parasit. 63: 642 650.

LEGUIA, G.: AREVALO, F. y VELIZ L. 1980. Prevalencia de Sarcocystis en ovinos y vacunos del Valle del Mantaro. Res. VI Cong. Nac. Ciencias Vet. Piurc. pp. 67. 